\title{
Mechanical Properties of Weathered Feldspar Sandstone after Experiencing Dry-Wet Cycles
}

\author{
Wen-bo An (iD), ${ }^{1}$ Laigui Wang, ${ }^{1}$ and He Chen ${ }^{2}{ }^{2}$ \\ ${ }^{1}$ College of Mechanics and Engineering, Liaoning Technical University, Fuxin 123000, China \\ ${ }^{2}$ College of Civil and Engineering, Liaoning Technical University, Fuxin 123000, China
}

Correspondence should be addressed to Wen-bo An; wb_an1992@163.com

Received 15 February 2020; Accepted 12 March 2020; Published 31 March 2020

Academic Editor: Raffaele Sepe

Copyright (c) 2020 Wen-bo An et al. This is an open access article distributed under the Creative Commons Attribution License, which permits unrestricted use, distribution, and reproduction in any medium, provided the original work is properly cited.

Weathering is one of the important geological hazards to many stone cultural relics carved on feldspar sandstone (such as the Datong Yungang Grottoes). To study the mechanical properties of the weathered Yungang Grottoes, feldspar sandstone was subjected to comparative dry-wet cycle tests with water-rock interaction (Group A) and salt-rock interaction (Group B). The variation patterns of the macroscopic physical and mechanical parameters as well as the micro/mesoscopic structures of the two groups of feldspar sandstone with the number of dry-wet cycles were measured. The results showed that for the Group A and Group B sandstones, as the number of dry-wet cycles increased the saturated water absorption and the longitudinal wave velocity increased, with the maximum variation rates reaching $28.02 \%, 36.98 \%, 16.20 \%$, and $33.27 \%$. The peak strength and elastic modulus gradually decreased, with the maximum variation rate reaching $48.53 \%, 73.44 \%, 26.61 \%$, and $72.39 \%$. The surface height deviation increased by as much as $1.06 \mu \mathrm{m}$ and $3.34 \mu \mathrm{m}$. The mechanism of weathering for the water-rock interaction included three effects, namely, the hydrolysis of the K-Na feldspar, the water swelling of the clay minerals such as kaolinite, and the dissolution of the soluble minerals. The mechanism of weathering for the salt-rock interaction included salt crystallization in the pores or fissures and chemical reactions between the minerals (such as feldspar and calcite) and sulfate, in addition to the above three effects. Therefore, the crystallization stress of the salt exerted the most notable effect on the deterioration of the feldspar sandstone. The results are expected to provide a reference for the stability evaluation and protection of the rock mass of the Grottoes.

\section{Introduction}

The Yungang Grottoes in Datong, Shanxi, are famous for their spectacular scenery, and they hold a pivotal position among the cultural relics of China. After thousands of years, most of the temples in the Yungang Grottoes have been destroyed, and some of the painted sculptures and murals have disappeared due to the impact of the natural environment. Over time, the Yungang Grottoes have been affected by both natural weathering and manmade sabotage. The weathering of the grottoes has been increasingly severe, leading to enormous consequences $[1,2]$. It was found from the field investigation that the Yungang Grottoes were scattered in huge lens-like feldspar sandstone (also known as Yungang Stone Buddha feldspar sandstone). The analysis of the weathering of grottoes no. 2, 3, and 12 showed that the severely weathered parts of the grottoes were generally at spots where there was abundant water or a water outlet. For example, the weathering of the rock faces near the ground surface was more severe than the weathering farther away from the ground surface. Additionally, the rock faces near the ground surface were relatively moist with the salt precipitated at part of the other areas, and the feldspar sandstone far from the ground surface was relatively well preserved. Over more than a thousand years, the seasonal and diurnal changes have caused the water in the Grottoes to stay in different states. In summer, the daytime temperature is high, so the water evaporates quickly and the Grottoes appear dry, but the nighttime temperature is low, so the Grottoes are in a moist state. In winter, the water is mostly in a liquid state during the day, when the evaporation is insignificant, and it freezes at night, when the temperature is 
low. Therefore, the water (salt) and temperature are the main factors affecting the weathering of the Grottoes.

To protect these stone cultural relics from weathering, the Yungang Grottoes Research Institute, among other organizations, has also implemented a large scale of protection work, including protection measures such as seepage prevention, dehumidification in the Grottoes, and drainage. Although these measures have had a protective effect, the problem of weathering has not been solved. Yan et al. and Qin et al. studied the weathering characteristics of the Yungang Grottoes and conducted tests on the soluble salt weathering in the Grottoes. The results show that the destruction of the Yungang Grottoes sandstone resulted from the combination of physical and chemical weathering. The water, salt solution, and temperature were the main influencing factors, and salt could aggravate the deterioration of the grotto structure [3-5]. Yao et al. investigated the mechanical properties of sandstone after dry-wet cycles [6]. The results showed that the mechanical indexes of the rock after dry-wet cycles decreased to varying extents. Coombes and Naylor obtained the weathering mechanism of rock through dry-wet cycle tests on limestone, granite, and concrete materials [7]. Torres-Suarez et al. examined the physical and mechanical properties of mudstone after dry-wet cycles [8]. The results showed that the main destruction mechanism of the layered mudstone started with microscopic scale fissure coalescence, and it manifested as physical and chemical deterioration. There have been numerous studies on the physical and mechanical properties of feldspar sandstone and ordinary sandstone, such as those above-mentioned [9-13]. However, there have been few studies on the damage mechanism of feldspar sandstone after dry-wet cycles from the perspective of chemical damage.

Therefore, for this study, feldspar sandstone of the same stratum and with similar lithology as that of feldspar sandstone where the Yungang Grottoes are scattered was selected. An experimental method was used that combined laboratory dry-wet cycle tests and macro-micro/mesoscopic observation to obtain the macroscopic physical and mechanical properties (e.g., saturated water absorption, longitudinal wave velocity, strength, elastic modulus, and deformation) as well as the variation patterns of the microstructure and the mesoscopic roughness of feldspar sandstone after wet-wet cycles. Based on this, the mechanical properties and the weathering mechanisms of feldspar sandstone after dry-wet cycles were analyzed.

\section{Material and Methods}

\subsection{Preparation of the Materials}

2.1.1. Preparation of the Feldspar Sandstone. Given the historical value of the Yungang Grottoes, the relevant department in this scenic area disallowed the collection of a large number of rock samples. Therefore, feldspar sandstone in the same stratum as that of the Yungang Grottoes was selected for the tests. The mineral composition and the average relative content of this feldspar sandstone and the statues of the Yungang Grottoes were compared and analyzed by X-ray diffraction (XRD). The results are shown in Figure 1 and Table 1 . In the figure, $Q$ is quartz, $P$ is $\mathrm{K}-\mathrm{Na}$ feldspar, $K$ is kaolinite, and $I$ is illite. It can be seen that the feldspar sandstone used in the experiment had similar lithology to that of the sandstone of the Yungang Grottoes, so it could represent the sandstone of the Yungang Grottoes. In the laboratory, the rock pieces of the feldspar sandstone were processed using a JKZS-100 automatic coring machine and a YBDQ-4 rock cutter according to the specifications (SL2642001, GB/T50266-99). After the processes of core drilling, cutting, polishing, grinding, cleaning, and drying, a standard sample of feldspar sandstone with a size of $\varphi 50 \mathrm{~mm}$ $\times 100 \mathrm{~mm}$ was finally obtained, as shown in Figure 2 .

2.1.2. Preparation of the Erosion Solution. According to the field investigation, the weathered grotto faces within $1 \mathrm{~m}$ from the ground are often moist, and a large amount of white salt appears in the dry season. Extensive research revealed that the white salt was sulfate $[14,15]$. Therefore, in the tests, the crystal salt of $\mathrm{Na}_{2} \mathrm{SO}_{4}$ (Glauber's salt) was used as the solute to prepare the saturated $\mathrm{Na}_{2} \mathrm{SO}_{4}$ solution as the erosion solution, and distilled water was used as a control. The standard samples were immersed in the prepared erosion solution to carry out the dry-wet cycle tests with water-rock interaction (Group A) and salt-rock interaction (Group B).

\subsection{Multiscale Experimental Techniques}

2.2.1. Dry-Wet Cycle Test. The dry-wet cycle test was conducted in reference to the requirements of the free immersion method in the specification (GB/T50266-99). The standard sample of feldspar sandstone was immersed in the erosion solution for $12 \mathrm{~h}$. The water level was first controlled at one-fourth of the height of the feldspar sandstone, and then the erosion solution was added after $2 \mathrm{~h}$ and $4 \mathrm{~h}$ to reach one-half and three-fourths of the height of the sample, respectively. After $6 \mathrm{~h}$, the sample was completely immersed in the erosion solution until the end of the immersion duration. Next, the sample was taken out and dried in the oven for $12 \mathrm{~h}$, with the drying temperature set to $50^{\circ} \mathrm{C}$ in consideration of the maximum temperature of around $60^{\circ} \mathrm{C}$ at the surface of the Grottoes in summer. Then all of the samples were taken out and cooled to room temperature, thus completing a dry-wet cycle of feldspar sandstone. The numbers of cycles were set to six levels $(0,5,10,15,20$, and 25 times T). After the dry-wet cycle test was completed at a level, the corresponding feldspar sandstone samples were removed to perform the subsequent tests.

\subsubsection{Experimental Study of the Physical Properties of} Feldspar Sandstone. After the test at each level was completed, the mass and the saturated water absorption of the feldspar sandstone were determined using an electronic balance (accuracy $0.01 \mathrm{~g}$ ). The longitudinal wave velocity of the feldspar sandstone was measured by an NM-4B-600 nonmetal ultrasonic detector. Before the measurement, the 


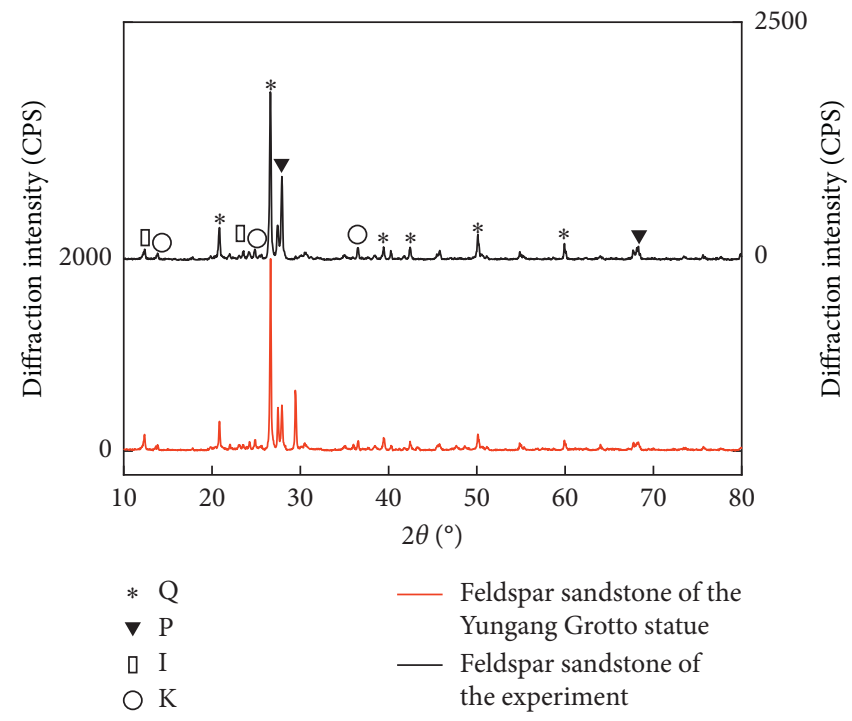

FIgURE 1: X-ray diffraction pattern.

TABLE 1: Average relative content of the minerals of the feldspar sandstones.

\begin{tabular}{|c|c|c|c|c|}
\hline \multirow{2}{*}{ Feldspar sandstones } & \multicolumn{4}{|c|}{ Average relative content of minerals (\%) } \\
\hline & Quartz & Potassium sodium feldspar & Kaolinite & Illite \\
\hline Yungang Grotto statue & 51 & 41 & 5 & 3 \\
\hline Experimental samples & 51 & 40 & 7 & 2 \\
\hline
\end{tabular}

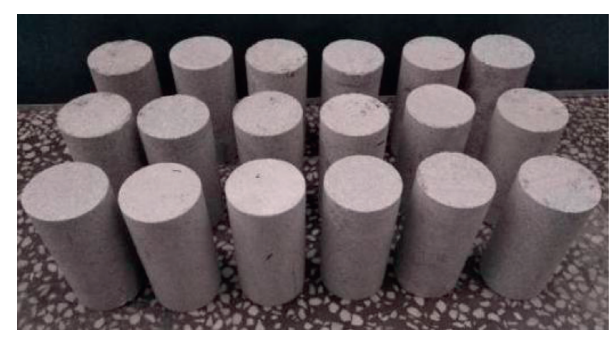

Figure 2: Standard feldspar sandstone samples.

detector was calibrated with a standard aluminum block to ensure the stability of its transmitted signal. During the measurement, a small amount of Vaseline was applied between the feldspar sandstone and the probe to ensure a close contact, and a $30-\mathrm{Hz}$ probe was used for the ultrasonic transducer.

2.2.3. Experimental Study of the Mechanical Properties of Feldspar Sandstone. After the test at each gradient was completed, a uniaxial compression test was carried out on the dry feldspar sandstone sample. At the same time, speckles were prefabricated on the relatively smooth lateral surface of the feldspar sandstone, and the evolution of the lateral deformation field of the feldspar sandstone under the load was observed. The mechanical properties of the dry feldspar sandstone were tested by a YAW-2000 hydraulic servo-tester. The uniaxial compression test adopted a displacement control loading mode with a loading rate set to
$0.005 \mathrm{~mm} / \mathrm{s}$. The lateral deformation field of the feldspar sandstone was observed by a digital speckle observation system, which mainly included a charge coupled device (CCD) camera, an analog -to - digital (A/D) converter, and a computer (PC) end. The resolution of the CCD camera was 1630 pixels $\times 1224$ pixels, the object surface resolution of the test was $0.0347 \mathrm{~mm} /$ pixel, the image acquisition rate was 2 frames/s, and the field of view was selected to be $30 \mathrm{~mm} \times 80 \mathrm{~mm}$. The loading system and the optical measurement system had to be performed synchronously.

2.2.4. Micro/Mesoscopic Observation of Feldspar Sandstone. The feldspar sandstone was scanned with a Hitachi S-3400N scanning electron microscope (SEM) to determine its apparent morphology and microstructure. Before the scanning, the feldspar sandstone (a cube with sides of approximately $10 \mathrm{~mm}$ ) was fixed on the stage with fixing glue, and the surface was sprayed with a gold coating of $5-10 \mathrm{~nm}$. The accelerating voltage was $20 \mathrm{kV}$.

The mineral composition and the relative content of the feldspar sandstone were determined by a Shimadzu XRD6100 X-ray diffractometer. Before the test, the feldspar sandstone fragments were ground into powder (less than 200 mesh) in an agate mortar. The light source was X-ray $\mathrm{Cu}$ target radiation $(\lambda=0.154056 \mathrm{~nm})$. An accelerating voltage of $20 \mathrm{kV}$, a current of $30 \mathrm{~mA}$, a scanning speed of $3^{\circ} / \mathrm{mm}$, and a scan range of $10^{\circ}$ to $80^{\circ}$ were used.

The surface roughness of the feldspar sandstone was determined by laser confocal scanning microscopy (LCSM). 
Each sample was measured by surface scanning its three areas, with a scan area of $1.28 \mathrm{~mm} \times 1.28 \mathrm{~mm}$. The measurement parameters included an $X Y Z$ fine scanning mode, an image pixel size of $1024 \times 1024$, an image size of $1280 \times 1280$, an object lens MPLFLN10×, and a zoom $1 \times$.

\section{Results and Analysis}

3.1. Comparative Analysis of the Apparent Properties of Feldspar Sandstone. The apparent properties of feldspar sandstone after the dry-wet cycle could directly reveal the degree of surface deterioration of the feldspar sandstone. Figures 3 and 4 show the apparent properties of the feldspar sandstone after a dry-wet cycle with water-rock interaction (Group A) and a salt-rock dry-wet cycle (Group B). It can be seen that apparent deterioration of the Group A feldspar sandstone was not notable in appearance from the outside, while the apparent deterioration of the Group B feldspar sandstone was very pronounced. In the early stage of the dry-wet cycle during salt-rock interaction ( 0 to $5 \mathrm{~T}$ ), the Group B feldspar sandstone was angular, and it had a smooth surface. As the number of cycles increased to enter the middle stage of the dry-wet cycle ( 5 to $20 \mathrm{~T}$ ), the feldspar sandstone was rounded, and the surface became rough. In the late stage of the dry-wet cycle $(20$ to $25 \mathrm{~T})$, this phenomenon of the feldspar sandstone increased, with a large amount of white crystals precipitated on the surface and a large amount of quartz particles spalling. This is mainly because the feldspar sandstone was primarily subjected to water softening and dissolution during the dry-wet cycle of water, while the feldspar sandstone was subjected to not only water softening-dissolution but also salt crystallization during the dry-wet cycle of the salt solution.

3.2. Comparative Analysis of the Physical Properties of Feldspar Sandstone. From the changes in the apparent properties of the feldspar sandstones in Groups A and B in Section 3.1, it can be seen that the water and salt solution could cause a certain degree of damage to feldspar sandstone. The effects of the dry-wet cycles on the physical properties of the feldspar sandstone are discussed in the following sections.

3.2.1. Comparative Analysis of the Saturated Water Absorption of Feldspar Sandstone. The saturated water absorption of the feldspar sandstone could be used to characterize the amount of internal pores or fissures. According to the specification (DL/T5368-2007), the saturated water absorption of feldspar sandstone is defined as

$$
w_{s}=\frac{m_{z}-m_{d}}{m_{d}} \times 100 \%
$$

where $w_{s}$ is the saturated water absorption of the feldspar sandstone, $m_{z}$ is the saturated water mass of the feldspar sandstone, and $m_{d}$ is the dry mass of the feldspar sandstone.

To obtain the complete variation pattern of the saturated water absorption of the feldspar sandstone in 0 to 25 dry-wet cycles, three samples at the level of 25 dry-wet cycles in the
Group A and Group B feldspar sandstones were selected for analysis. The average saturated water absorption of the feldspar sandstone after the dry-wet cycles was calculated using formula (1). The results are shown in Figure 5. It can be seen that as the number of dry-wet cycles increased, the saturated water absorption of the Group A and Group B feldspar sandstones gradually increased, reaching the maximums of $5.94 \%$ and $6.26 \%$, respectively. Therefore, the dry-wet cycle could promote the expansion of pores and fissures in the feldspar sandstone, and the salt-rock interaction was more pronounced than the water-rock interaction.

3.2.2. Comparative Analysis of the Longitudinal Wave Velocity of Feldspar Sandstone. Longitudinal wave velocity is one of the important indicators for evaluating material damage. Because ultrasonic waves have different propagation velocities in different media, longitudinal wave velocity can characterize the development of the internal pores or fissures of rock. As described in this section, the NM-4B nonmetal ultrasonic detection analyzer was used to measure the longitudinal wave velocities of the Group A and Group B feldspar sandstone after different numbers of dry-wet cycles. To avoid the error of the experimental results due to the difference between the individual feldspar sandstone samples, the change rate of the longitudinal wave velocity was used as an evaluation indicator. The results are shown in Figure 6 . The change rate of the longitudinal wave velocity, $R$, is defined as

$$
R=\frac{v_{0}-v_{n}}{v_{0}} \times 100 \%,
$$

where $v_{0}$ is the initial longitudinal wave velocity of the feldspar sandstone and $v_{n}$ is the longitudinal wave velocity of the feldspar sandstone after $n$ dry-wet cycles.

It can be seen from Figure 6 that as the number of drywet cycles increased, the longitudinal wave velocities of the Group A and Group B feldspar sandstones gradually decreased, and the change rates of the wave velocity gradually increased, reaching the maximum values of $16.20 \%$ and $33.27 \%$. The decrease in wave velocity indicated that the drywet cycle could promote the development of pores or fissures in the feldspar sandstone. In other words, the development was improved with the increase in the number of dry-wet cycles. The change rate of the wave velocity of Group A was lower than that of Group B, indicating that the salt crystallization had a great effect on the pores or fissures in the feldspar sandstone, consistent with the results corresponding to the saturated water absorption.

3.3. Comparative Analysis of the Mechanical Properties of Feldspar Sandstone. It was concluded from the above tests that the dry-wet cycle could cause a certain degree of damage to the apparent properties and physical properties of the feldspar sandstone. It could be preliminarily predicted that the dry-wet cycle could degrade the mechanical properties of feldspar sandstone. Therefore, the uniaxial compressive strength, elastic modulus, and lateral deformation of the 


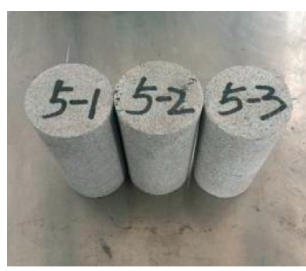

(a)

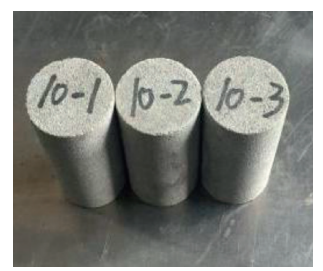

(b)

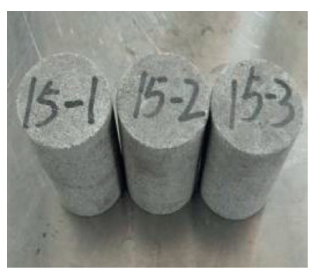

(c)

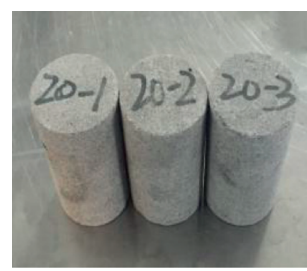

(d)

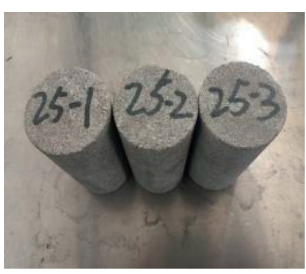

(e)

Figure 3: Apparent properties of the feldspar sandstones (group A) after a water-rock dry-wet cycle. (a) 5 T. (b) $10 \mathrm{~T}$. (c) $15 \mathrm{~T}$. (d) $20 \mathrm{~T}$. (e) $25 \mathrm{~T}$.

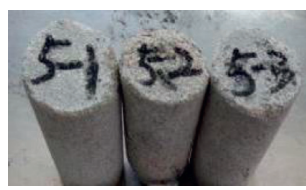

(a)

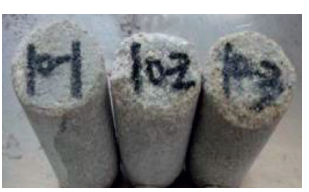

(b)

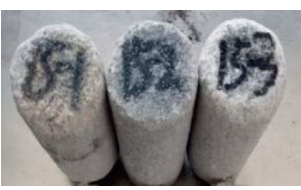

(c)

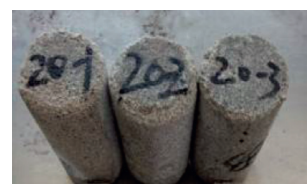

(d)

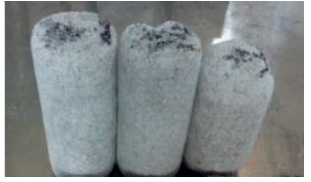

(e)

Figure 4: Apparent properties of the feldspar sandstones (group B) after a salt-rock dry-wet cycle. (a) 5 T. (b) 10 T. (c) 15 T. (d) 20 T. (e) $25 \mathrm{~T}$.

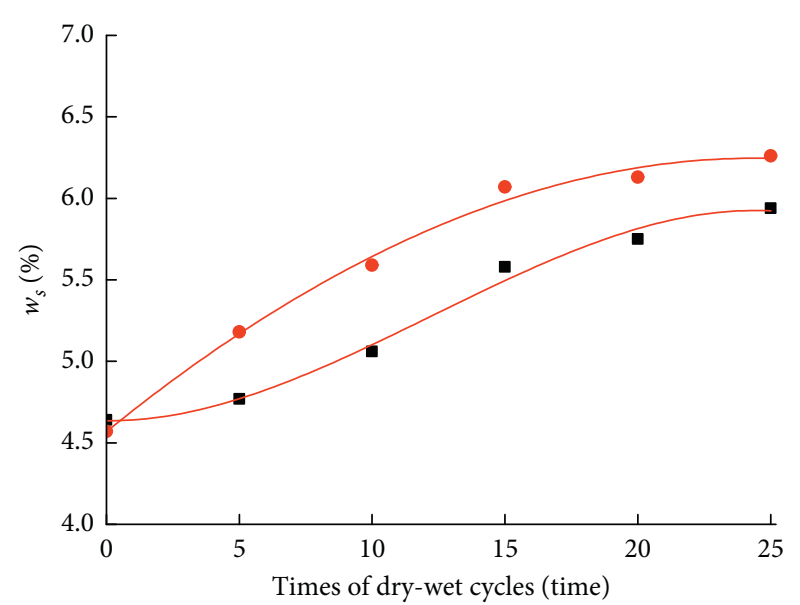

- Group A

- Group B

FIGURE 5: Average saturated water absorption rate of the feldspar sandstones after a dry-wet cycle.

feldspar sandstone after dry-wet cycles were mainly studied, as described in this section.

3.3.1. Comparative Analysis of the Stress-Strain Curves of Feldspar Sandstone. To avoid the influence of differences between individual feldspar sandstone samples on the test results, three parallel samples from each group were subjected to water-rock and dry-wet cycles with salt-rock interactions. After uniaxial compression tests, the test results of each group of sandstone were found to be roughly the same. Therefore, to avoid unnecessary repetitive efforts, the stress-strain curves of the Group A samples numbered 0-1, $5-1,10-1,15-3,20-1$, and 25-2 and of the Group B samples numbered $0-1,5-1,10-2,15-3,20-1$, and 25-1 were selected for analysis. The results are shown in Figure 7.

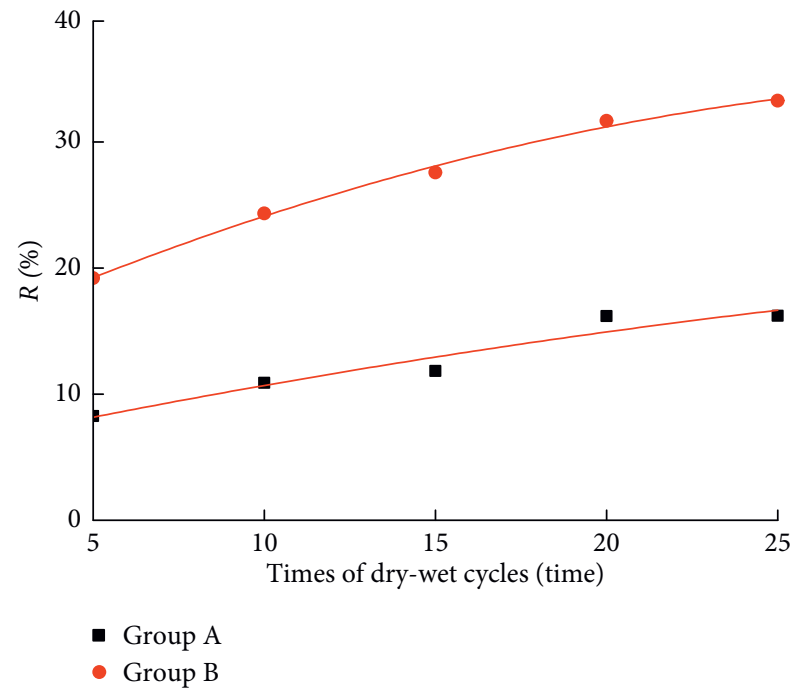

FIGURE 6: Longitudinal wave velocity change rates of the feldspar sandstones after a dry-wet cycle.

It can be seen from Figure 7(a) that the uniaxial loading of the feldspar sandstone after the dry-wet cycles with waterrock interaction generally show a trend of first increasing and then decreasing, and the curve has a notable compaction stage and destruction stage. The feldspar sandstone stress increased gradually with the increase in the strain, and after reaching the peak, the stress dropped to zero almost rapidly, indicating that feldspar sandstone was very brittle. The brittle property of the feldspar sandstone still existed even after multiple dry-wet cycles. The peak strength of the feldspar sandstone was greatly affected by the dry-wet cycles. As the number of dry-wet cycles increased, the peak strength decreased gradually. Additionally, in terms of apparent phenomenon, there was the sound of notable damage and the ejection of a small number of rock pieces before the 


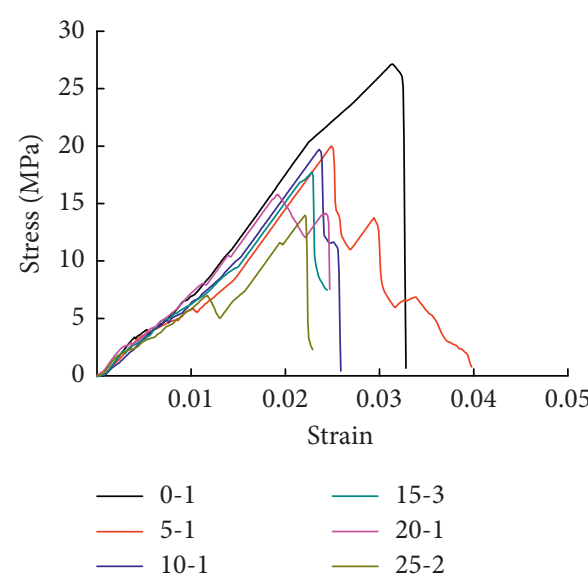

(a)

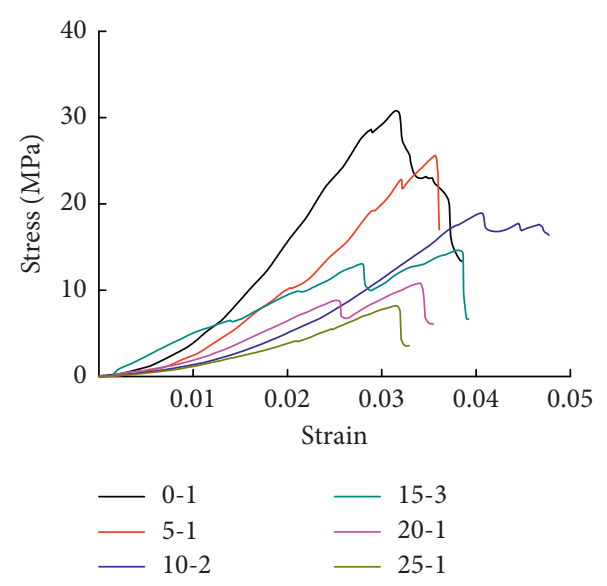

(b)

FIgURE 7: Stress-strain curves of the feldspar sandstones after a dry-wet cycle. (a) Group A. (b) Group B.

critical destruction of the sample, and the cracks at destruction extended mainly in the vertical direction (longitudinal). This was mainly because water entered the interior of the feldspar sandstone when the feldspar sandstone was subjected to dry-wet cycles, softening the internal structure of the feldspar sandstone and dissolving part of the mineral components. Therefore, as the number of dry-wet cycles increased, the microcracks would coalesce when the feldspar sandstone was loaded, eventually forming main cracks with a gradually increasing number [16].

It can be seen from Figure 7(b) that the stress-strain curves of the feldspar sandstone after the dry-wet cycles with salt-rock interaction all experienced the initial stage, compaction stage, softening stage, and destruction stage. The strength of the feldspar sandstone rapidly decreased after reaching the peak strength, indicating that although the feldspar sandstone was subjected to multiple dry-wet cycles with the salt solution, the feldspar sandstone still showed remarkable brittle properties when loaded to destruction, whereas the brittle properties decreased with the increase in the number of dry-wet cycles. A comparison of the stressstrain curves with different erosion cycles showed that as the peak stress was approached, the stress was re-adjusted to various extents. In the stress-strain curve, the stress readjustment manifested as the curve dropped suddenly and then continues to rise. That is to say, when the rock was subjected to loading, the external part of the rock was damaged first, and part of the load was released instantly due to the local destruction. At the same time, the load continued to be carried by the internal undamaged structure, causing the internal stress to increase rapidly due to the reduction of the load-carrying area. A stress readjustment could be used to characterize the nonuniform load-carrying capacity of materials. The amount of stress readjustment of the Group B feldspar sandstone increased with the increase in the number of dry-wet cycles with salt-rock interaction, indicating the nonuniform structural damage to the Group B feldspar sandstone. This result could also be verified by the apparent phenomenon. After the dry-wet cycles, the surface layer of the feldspar sandstone under loading was the first to be damaged, as manifested by the spalling of many rock pieces from the surface, which was more pronounced with the increase in the number of dry-wet cycles. This result is consistent with the phenomenon of flaky weathering at the Grottoes. The stress-strain characteristics of the feldspar sandstone essentially reflected the damage caused by the drywet cycles with a salt solution. The damage process occurred continuously from the outside to the inside, resulting in the nonuniformity of the damage area of the feldspar sandstone. This provided a reference for the stability of the rock mass or pillar [17].

Figure 8 shows the curves of the uniaxial compressive strength and the elastic modulus of the Group A and Group $B$ feldspar sandstones. It can be seen that as the number of dry-wet cycles increased from 0 to 25 for the Group A samples, the compressive strength decreased from 27.14 MPa to $13.97 \mathrm{MPa}$ with a reduction of $48.53 \%$, and the elastic modulus decreased from $981 \mathrm{MPa}$ to $720 \mathrm{MPa}$ with a reduction of $26.61 \%$. For the Group B samples, the compressive strength decreased from $30.80 \mathrm{MPa}$ to $8.18 \mathrm{MPa}$ with a reduction of $73.44 \%$, and the elastic modulus decreased from $1532 \mathrm{MPa}$ to $423 \mathrm{MPa}$ with a reduction of $72.39 \%$. Therefore, the mechanical properties of the feldspar sandstone were reduced more by the dry-wet cycles with the salt solution, and the damage effect of the crystallization stress on the feldspar sandstone was more remarkable.

3.3.2. Comparative Analysis of the Lateral Strain of the Feldspar Sandstone. An observation system using the digital speckle correlation method (DSCM) was employed to observe and analyze the deformation and destruction characteristics of the feldspar sandstone after the dry-wet cycles of the Group A and B samples in order to obtain the evolution process of the lateral strain field. Due to the large amount of variables and data, the Group A and B sandstone samples with the most notable damage (numbered 25-2 and 25-1) were selected for analysis. The results are shown in Figures 9 and 10. According to the literature [18], the lateral strain evolution process could be 


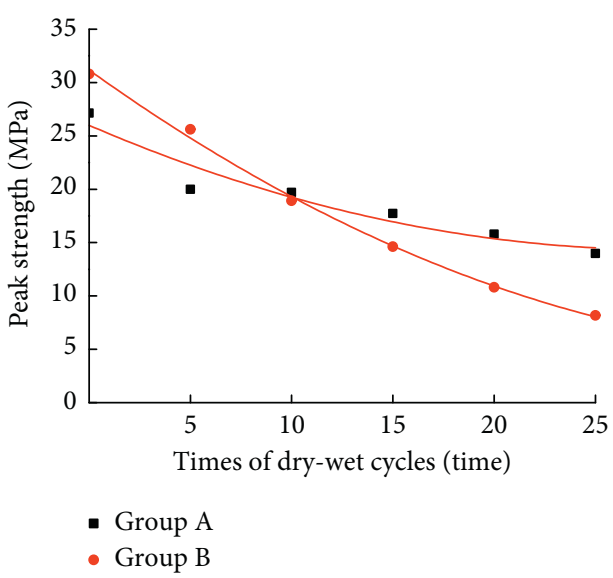

(a)

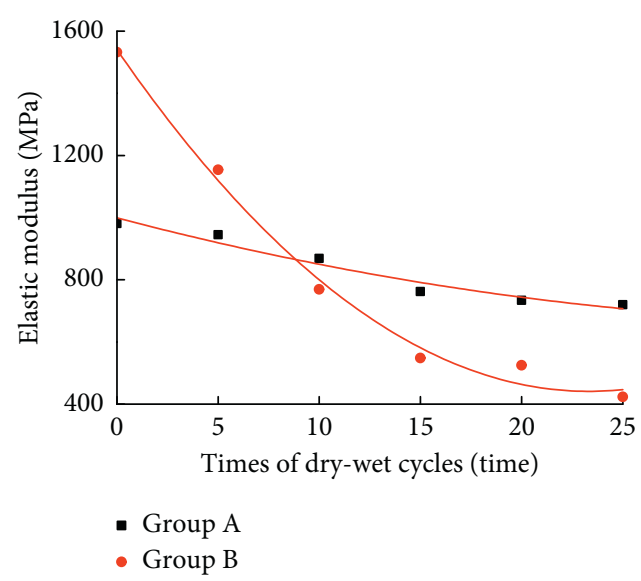

(b)

Figure 8: Mechanical strength of the feldspar sandstones after the dry-wet cycles. (a) Peak strength. (b) Elastic modulus.

roughly divided into four stages, namely, the uniform distribution stage, nucleation stage, localization stage, and destruction stage. On the stress-strain curve, the representative points of the four stages in the evolution of the deformation field were selected, and the stress at each representative point was calculated, as shown in Figures 9(a) and 10(a). Figures 9(b) and 10(b) show the destruction patterns of the sample, and Figures 9(c)-9(f) and $10(\mathrm{c})-10$ (f) show the contours of the lateral shear strain at each representative point. The range of the horizontal and vertical coordinates of the field of view in the figure is $30 \mathrm{~mm} \times 80 \mathrm{~mm}$.

The evolution process of the lateral deformation field actually reflected the crack activity within the feldspar sandstone [19]. It can be seen from Figures 9 and 10 that the strain characteristics were remarkable at each stage of the evolution process of the lateral shear strain field. The uniform distribution stage was located in the initial stage of the stress-strain curve, for which the shear strain was small and uniformly distributed. As the stress-strain curve entered the linear elastic phase, the stress level rose, which compacted the sample and caused microcracks to appear. Accordingly, a spherical strain region appeared in the shear strain contour map; that is, the nucleation stage formed. At the softening stage of the stress-strain curve before the peak, the stress level of the feldspar sandstone is high, macroscopic cracks began to appear, and the lateral shear strain field changed from the original nucleus shape to a band shape; that is, the strain localization formed, which was the most important phenomenon before the destruction of the feldspar sandstone. After this stage, the stress level of the feldspar sandstone sample was expected to reach the peak and the overall structure was about to be destroyed. A comparison of the destruction pattern diagram and the strain contour map of the feldspar sandstone revealed that the main macroscopic cracks occurred in the strain localization area. Therefore, the deformation and destruction characteristics of the feldspar sandstone could be studied by observing the lateral strain field of the sample.
3.4. Comparative Analysis of the Microscopic Characteristics of Feldspar Sandstone. The above series of physical and mechanical tests was mainly used to analyze the deterioration of the feldspar sandstone after dry-wet cycles from a macroscopic point of view. However, the macroscopic physical and mechanical behavior of the feldspar sandstone mainly resulted from the continuous change of its $\mathrm{mi}-$ crostructure. In recent years, the observation of the microscopic properties of rock materials has gradually become an important and universal means of research. Past researchers [20, 21] used micro/mesoscopic observation equipment to study the destruction mechanism of modified materials such as cement mortar and mudstone, and the relationship between their research results and the macroscopic destruction mechanism was widely recognized. Therefore, it is important to study the micro/mesoscopic changes of feldspar sandstone under dry-wet cycles in order to reveal the deterioration mechanism of feldspar sandstone. In this section, the deterioration processes of feldspar sandstone after dry-wet cycles were comparatively analyzed from the micro/mesoscopic perspective using the means such as XRD, SEM, and laser scanning confocal microscope (LSCM).

3.4.1. Comparative Analysis of the Mineral Composition of Feldspar Sandstone. Figure 11 shows the XRD patterns of the Group A and Group B feldspar sandstones after drywet cycles. In the figure, Y-0 represents the curve of the dry undisturbed feldspar sandstone, A-25-2 is the curve of the Group A feldspar sandstone after 25 dry-wet cycles, and B-25-1 is the curve of the Group B feldspar sandstone after 25 dry-wet cycles, where Q, P, K, and I denote quartz, sodium potassium feldspar, kaolinite, and illite, respectively. The relative content of the minerals in the feldspar sandstone was analyzed by the semiquantitative analysis software Xpert Highscore Plus, as shown in Table 2 .

It can be seen from Figure 11 and Table 2 that quartz was the most abundant component in the feldspar sandstone, and 


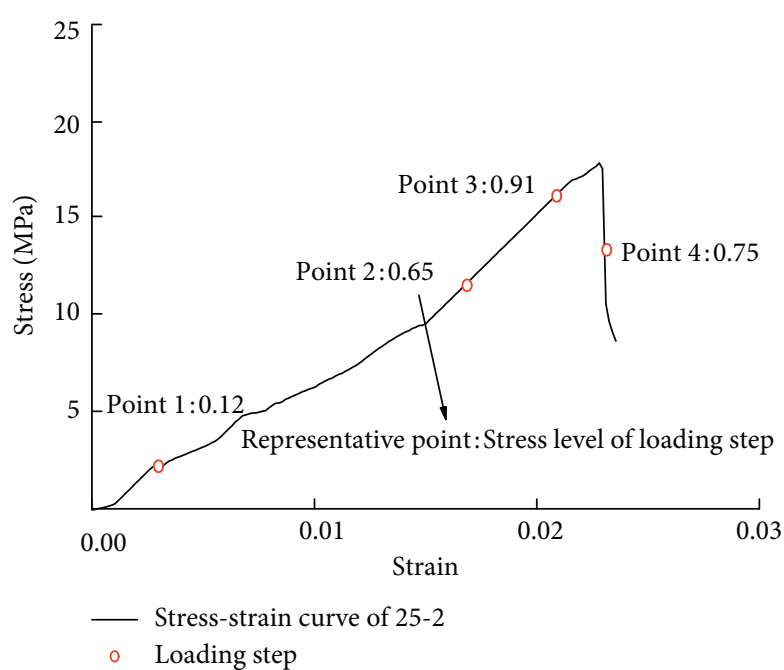

(a)

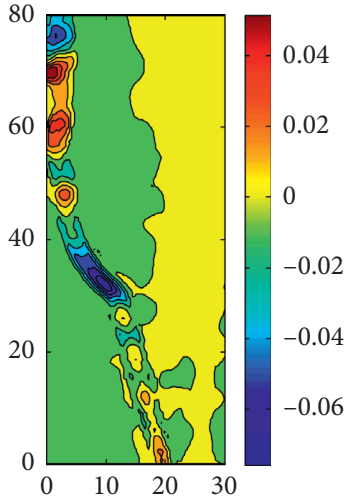

(d)
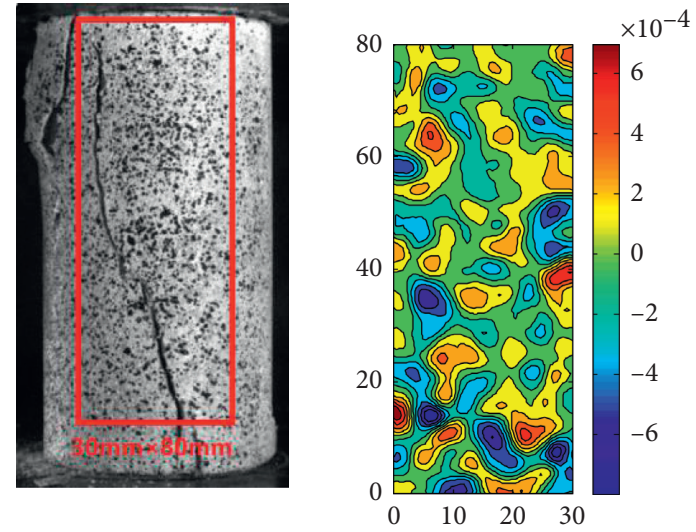

(b)

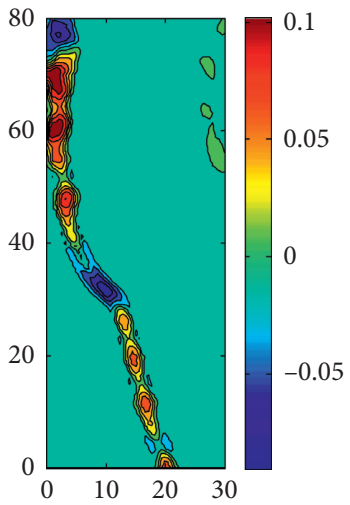

(e) (c)

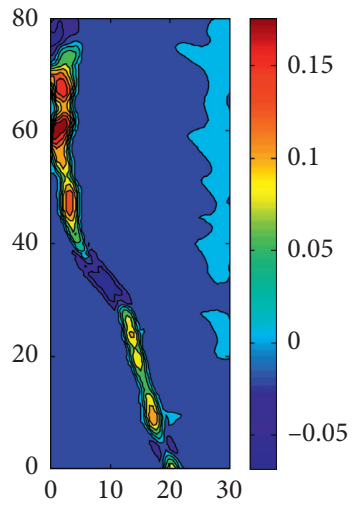

(f)

Figure 9: Evolution process of the lateral strain field of the feldspar sandstones (Group A) after the dry-wet cycles. (a) The curve of the representative points. (b) Destruction pattern. (c) Point 1 (d) Point 2. (e) Point 3. (f) Point 4.

it had the highest diffraction intensity. Compared with undisturbed feldspar sandstone, the Group A and Group B feldspar sandstones differed by a small amount in terms of the diffraction intensity and composition relative content, indicating that the dry-wet cycles with water and salt solution had little effect on quartz, which was also the reason for the stability of the quartz. In addition, the diffraction intensity and the relative content of the K-feldspar and illite in Group A and Group B were low, and those of kaolinite were high. This was because of the hydrolysis of feldspar to form kaolinite. The hydrolysis reaction of the water and feldspar was

$$
2 \mathrm{KAlSi}_{3} \mathrm{O}_{8}+2 \mathrm{H}^{+}+\mathrm{H}_{2} \mathrm{O}=2 \mathrm{~K}^{+}+4 \mathrm{SiO}_{2}+\mathrm{Al}_{2}\left(\mathrm{Si}_{2} \mathrm{O}_{5}\right)(\mathrm{OH})_{4}
$$

Compared with the attributes of the Group A feldspar sandstone, the diffraction intensity and relative content of the feldspar in the Group B feldspar sandstone decreased and those of the kaolinite in the Group B increased. This was because Groups A and B both had aqueous solutions while Group B also contained sulfate solution. Therefore, in addition to the hydrolysis reaction, there should have also been a reaction between the sulfate and the feldspar as follows:

$$
\begin{aligned}
& 2 \mathrm{Na}\left(\mathrm{AlSi}_{3} \mathrm{O}_{8}\right)_{2}+9 \mathrm{H}_{2} \mathrm{O}+\mathrm{H}_{2} \mathrm{SO}_{4}=\mathrm{Al}_{2} \mathrm{O}_{3} 2 \mathrm{SiO}_{2} \cdot 2 \mathrm{H}_{2} \mathrm{O} \\
& +\mathrm{Na}_{2} \mathrm{SO}_{4}+4 \mathrm{H}_{4} \mathrm{SiO}_{4}
\end{aligned}
$$

The reaction between the feldspar and the sulfate produced kaolinite and at the same time released sodium ions to form more sulfate. As a result, sulfate contained in the water not only damaged the structure of the feldspar sandstone but also continuously damaged the feldspar sandstone due to the recycling of the sulfate ions, which was consistent with the pattern of the macroscopic mechanical changes.

3.4.2. Comparative Analysis of Feldspar Sandstone. The microscopic surface morphologies of the Group $A$ and Group B feldspar sandstones for dry-wet cycles are shown in Figures 12 and 13. It can be clearly seen from the apparent morphology of the feldspar sandstone after no dry-wet cycles that the composition of the feldspar sandstone included quartz particles and minerals such as feldspar. The surfaces of the quartz particles were relatively flat and smooth, acting as the skeleton, while minerals such as 


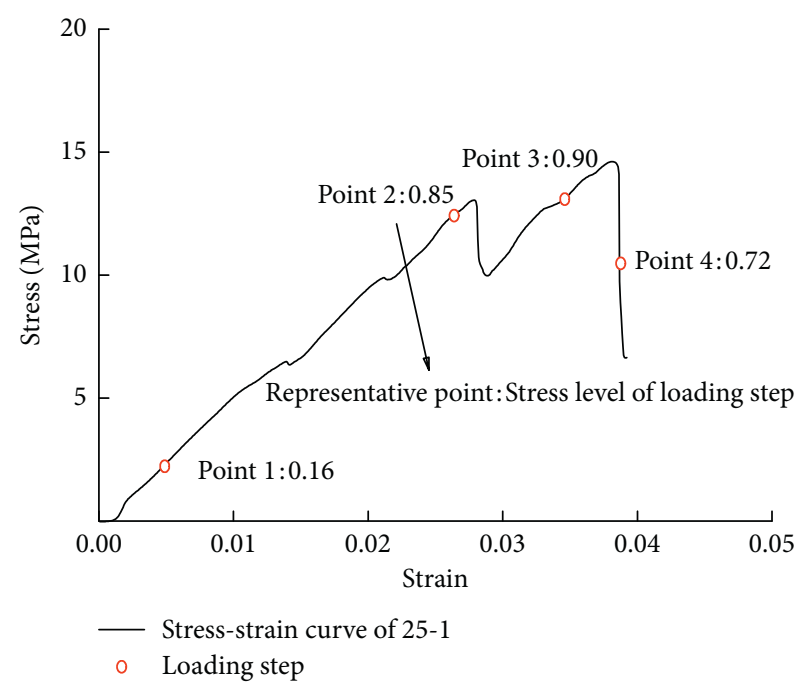

(a)

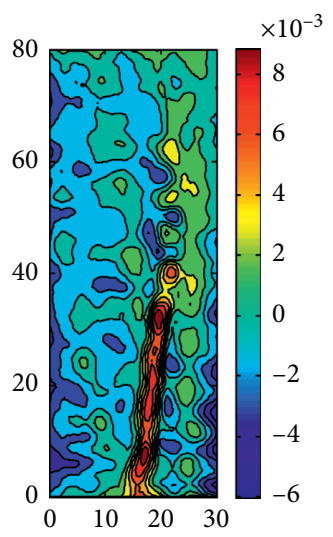

(d)
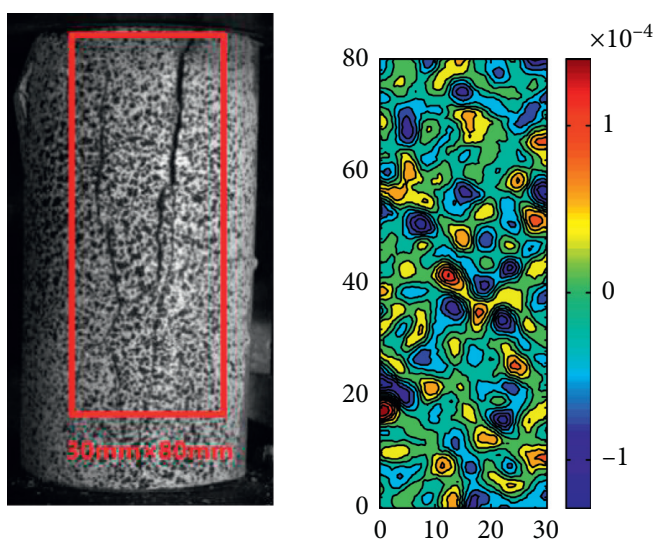

(b)

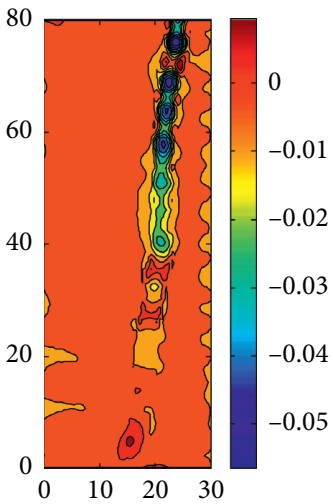

(e) (c)

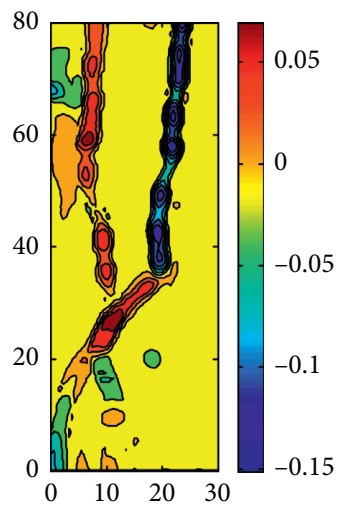

(f)

Figure 10: Evolution process of the lateral strain field of the feldspar sandstones (Group B) after the dry-wet cycles. (a) The curve of the representative points. (b) Destruction pattern. (c) Point 1. (d) Point 2. (e) Point 3. (f) Point 4.

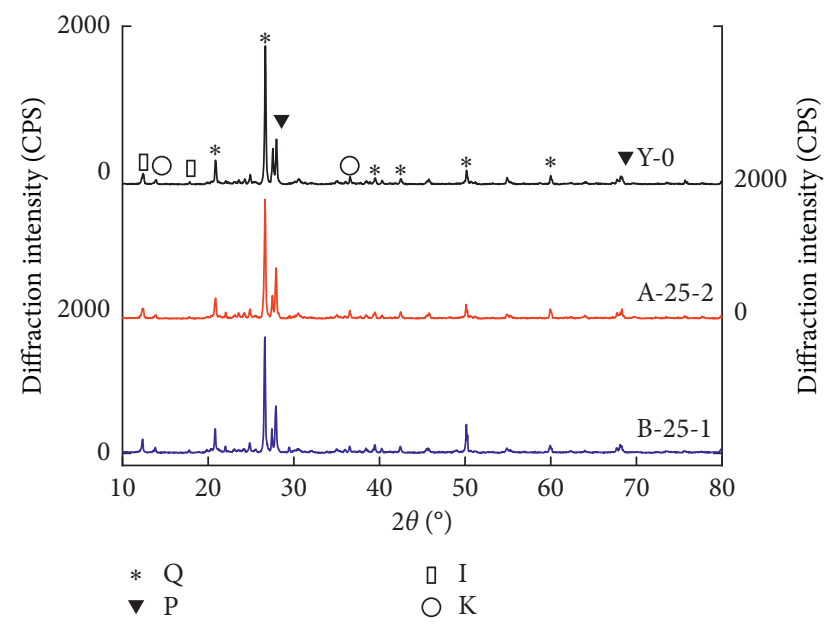

FIGURE 11: X-ray diffraction of the feldspar sandstones before and after the dry-wet cycles.
TABLE 2: Relative content of the minerals in the feldspar sandstones of Groups A and B after the dry-wet cycles.

\begin{tabular}{lcccc}
\hline \multirow{2}{*}{ Samples } & \multicolumn{4}{c}{ Relative content of minerals (\%) } \\
& Quartz & Potassium sodium feldspar & Kaolinite & Illite \\
\hline Y-0 & 51 & 41 & 5 & 3 \\
A-25-2 & 50 & 36 & 12 & 2 \\
B-25-1 & 51 & 28 & 19 & 1 \\
\hline
\end{tabular}

feldspar were relatively coarse, acting as cementing material filled between particles, along with the pores and fissures that existed between them acting as the linkage. It can be seen from Figure 12 that the internal structure of the undisturbed feldspar sandstone had a clear outline of the particles on the scan, the particles and the cementing material were notably divided, and the particles were aligned closely and neatly. As the number of dry-wet cycles increased, the feldspar sandstone had a lowered surface compactness and a loose structure, and the mineral particles had rough surfaces with 


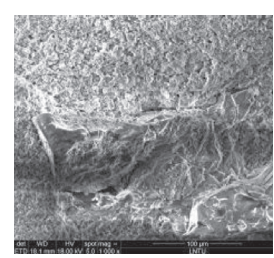

(a)

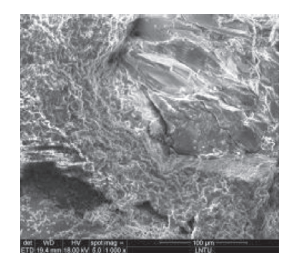

(b)

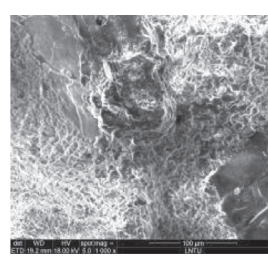

(c)

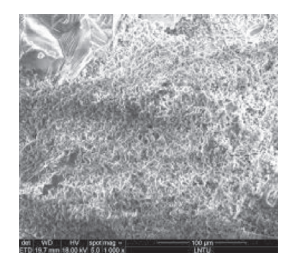

(d)

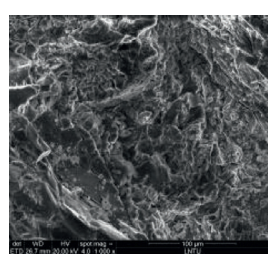

(e)

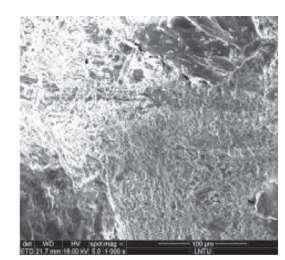

(f)

Figure 12: Microstructure of the feldspar sandstones (Group A) after the dry-wet cycles. (a) 0 T. (b) 5 T. (c) 10 T. (d) 15 T. (e) 20 T. (f) 25 T.

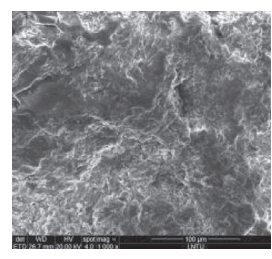

(a)

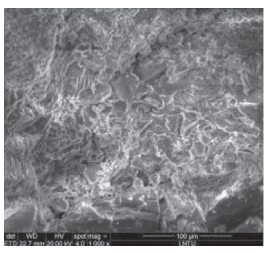

(b)

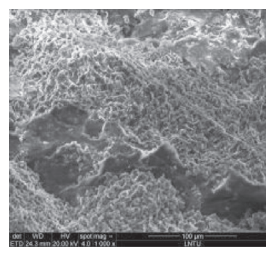

(c)

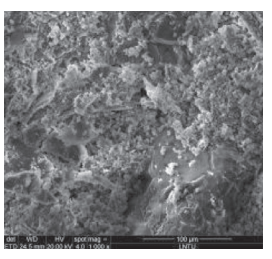

(d)

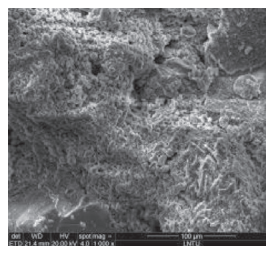

(e)

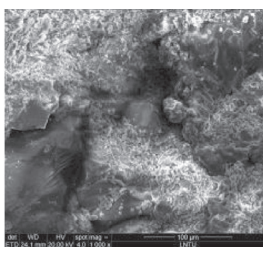

(f)

Figure 13: Microstructure of the feldspar sandstones (Group B) after the dry-wet cycles. (a) 0 T. (b) 5 T. (c) 10 T. (d) 15 T. (e) 20 T. (f) 25 T.

many small particles. This was largely related to the softening and dissolution of the feldspar sandstone by water.

It can be seen from Figure 13 that after 0 to 5 dry-wet cycles, there was a small amount of near-spherical salt crystals in the pores or fissures. As the number of cycles increased, the salt content in the pores gradually increased, and it was enriched around the quartz particles. Based on the above analysis, there were cementing materials dominated by feldspar minerals around the quartz particles. The presence of the salt indicated that the crystallization stress mainly affected the relatively weak cementing materials. It was also found that as the number of cycles increased, crystallized salt first filled the tiny pores and then the large pores. The evaporation of water was the internal driving force of salt crystallization. The small volume of water in the tiny pores made the evaporation relatively easy, and it was easy to fill the relatively small space with salt crystals. Salt crystals accumulated continuously during the dry-wet cycles. The saturated salt solution first eroded the pores or fissures and even the microcracks of feldspar sandstone. As the water evaporated continuously, the salt crystallized continuously on the walls of the pores or the fissures. After a certain number of times, the salt filled the entirety of the pores or fissures, and then compressive stress began to be generated. When the compressive stress was higher than the strength of the relatively weak minerals (feldspar cement), microdestruction, which may also be called microdamage, occurred inside the feldspar sandstone. As the number of times of crystallization further increased, the damage to the feldspar sandstone gradually increased. Such damage to the feldspar sandstone had a specific directionality. This was because the solution gradually entered from the outside to the inside as the feldspar sandstone was immersed in solution, so the damage to the feldspar sandstone also needed to progress from the outside to the inside. This result is consistent with that of [3], but it is different from the earlier findings of $[22,23]$.
3.4.3. Comparative Analysis of the Surface Roughness of the Feldspar Sandstone. Roughness measurement is usually applied to the friction and wear of metal materials, while the roughness measurement of rock materials is only used for the purpose of fissure characterization. In this section, the principle of roughness measurement is introduced to characterize the degree of damage to the feldspar sandstone. The cored and ground feldspar sandstone samples initially had a flat and smooth surface. After different numbers of dry-wet cycles, the samples may have had different damages, as also manifested on their surfaces. This has already been described in the analysis of the apparent phenomenon (Section 3.1). The roughness of the outer surface of the feldspar sandstone after these different numbers of dry-wet cycles could be measured to characterize the damage to the feldspar sandstone from a different perspective. Three areas were taken from each sample for measurement, and the final roughness was taken as the average of the data for the three areas.

Belem et al. [24] proposed four typical three-dimensional surface morphology parameters, namely, surface height deviation $S_{a}$, surface height distribution standard deviation $S_{q}$, surface skewness $S_{s k}$, and surface kurtosis $S_{k u}$. Among them, $S_{a}$ and $S_{q}$ are generally used to express the height of the surface morphology of a material, $S_{k u}$ is used to describe the steepness of the surface morphology of a material, and $S_{s k}$ is used to describe the asymmetry of the surface height distribution. In this study, $S_{a}$ was selected as the parameter for roughness characterization. It is calculated as

$$
S_{a}=\frac{1}{M N} \sum_{k=0}^{M-1} \sum_{l=1}^{N-1}\left|z\left(x_{k}, y_{l}\right)-u\right| \text {, }
$$

where $u=(1 / M N) \sum_{k=0}^{M-1} \sum_{l=1}^{N-1} z\left(x_{k}, y_{l}\right)$, and $M$ and $N$ are the length and width, respectively, of the three-dimensional surface image; $z\left(x_{k}, y_{l}\right)$ is the height at the point $\left(x_{k}, y_{l}\right)$.

Table 3 shows the measured values of the height deviations $S_{a}$ of the Group A and B feldspar sandstones after the 
TABLE 3: Height deviations $S_{a}$ of the feldspar sandstone surface in Groups A and B after the dry-wet cycles.

\begin{tabular}{lcccccccc}
\hline \multirow{2}{*}{ Number of wet and dry cycles } & \multicolumn{8}{c}{ Measurement area } \\
& \multicolumn{2}{c}{ Surface height deviation of group A $(\mu \mathrm{m})$} & \multicolumn{2}{c}{ Surface height deviation of group B $(\mu \mathrm{m})$} \\
& No. 1 & No. 2 & No. 3 & Average value & No. 1 & No. 2 & No. 3 & Average value \\
\hline 0 & 4.37 & 5.21 & 5.52 & 5.03 & 4.84 & 5.52 & 4.99 & 5.12 \\
5 & 5.47 & 5.34 & 5.39 & 5.40 & 5.47 & 7.43 & 5.99 & 6.30 \\
10 & 5.57 & 5.84 & 5.48 & 5.63 & 6.36 & 6.15 & 6.68 & 6.40 \\
15 & 5.96 & 5.84 & 5.68 & 5.83 & 7.01 & 6.44 & 8.21 \\
20 & 5.84 & 5.83 & 6.19 & 5.95 & 7.47 & 10.62 & 6.67 & 8.22 \\
25 & 5.80 & 6.21 & 6.26 & 6.09 & 9.36 & 7.53 & 8.78 \\
\hline
\end{tabular}

dry-wet cycles. It can be seen that as the number of dry-wet cycles increased, the surface deviation of the feldspar sandstone generally showed an upward trend. This indicates that the roughness of the outer surfaces of the Group A and Group B feldspar sandstones gradually aggravated, from 0 cycle to 25 cycle, the average value increased by $1.06 \mu \mathrm{m}$ and $3.34 \mu \mathrm{m}$, respectively, due to the impact of the dry-wet cycles on the feldspar sandstone. The above microscopic morphology analysis revealed that the quartz particles on the surface of the feldspar sandstone had a hard texture and stable properties, making it difficult to damage. It was hence only possible that the relatively weak cementing materials of the feldspar were damaged and they fell off, eventually causing quartz particles to be exposed on the surface and thus increasing the surface roughness. This also confirmed the conclusion of the particles falling in the macroscopic apparent analysis. The increase in the surface roughness also indicated from another angle that the damage to the feldspar sandstone caused by the dry-wet cycles was increasingly aggravated. A comparison of the data of Group A and B found that the surface roughness of the feldspar sandstone after salt crystallization was much higher than that after dry-wet cycles, consistent with the variation pattern of the macroscopic mechanical properties. Additionally, the relatively large rate of increase in the surface height deviation was attributed to the considerable effect of salt crystallization, which caused the weak cementing material to be destroyed rapidly. This effect was much more remarkable than the mere effect of softening and dissolution caused by water. The conclusion drawn from surface roughness analysis is essentially the same as the variation pattern of the macroscopic mechanical properties.

\section{Weathering Mechanism of Feldspar Sandstone}

4.1. Analysis of the Weathering Mechanism of the Water-Rock Interaction. At present, the mechanistic analysis of waterrock interaction is conducted mainly from the single perspective of macroscopic mechanical properties or microscopic observation, whereas the analysis of the mechanism of water-rock interaction from different scales is still rare.

According to the analysis of the macroscopic physical and mechanical properties, the main physical and mechanical parameters of the feldspar sandstones after multiple dry-wet cycles were all weakened. In particular, the wave velocity, compressive strength, and elastic modulus were reduced by $16.20 \%, 48.53 \%$, and $26.61 \%$, respectively, and the saturated water absorption increased by $28.02 \%$. The variation of these measured macroscopic physical and mechanical parameters represented the deterioration of the overall structure of the feldspar sandstone after a specific number of dry-wet cycles and, in essence, the change in the micro/ mesoscopic structure, such as the composition, structure, and pores or fissures of feldspar sandstone. After the component identification and microscopic observation of the feldspar sandstone, the primary internal structure of the feldspar sandstone that was not affected by the dry-wet cycles could be represented as shown in Figure 14(a). The primary internal structure of the feldspar sandstone mainly included two parts: the matrix and the skeleton. The matrix included feldspar, clay, and the pore and fissure structure. The skeleton was mainly composed of quartz particles with a hard texture and stable properties. The matrix and the skeleton mainly formed a stable feldspar sandstone structure by cementation. The composition of the single quartz particle as the core surrounded by various components of the matrix was regarded as a simple unit of feldspar sandstone. The unit contained all the basic elements in the composition of feldspar sandstone, as shown in Figure 14(c). During the dry-wet cycles, water first invaded from the outside to the inside along the primary pores or fissures in the unit. The primary pores became the main sites for the water effect. Based on this, secondary cracks were generated by the following three effects:

(1) Since the sandstone samples in this study were made of feldspar sandstone, the K-Na feldspar in the unit chemically reacted with water to form kaolinite (formula (3)). In the process, due to the different physical properties (composition and density) and different spaces occupied by the new and old materials, a large number of microcracks, that is, secondary cracks, were generated.

(2) The clay minerals in the unit had the characteristics of water swelling. The clay minerals included not only kaolinite (which was secondary clay) formed by the reaction between water and feldspar but also the primary clay of feldspar sandstone. When the clay minerals experienced water swelling, a large number of secondary cracks were produced.

(3) The unit contained a large amount of soluble minerals such as feldspar or kaolinite. These minerals were dissolved in water in the form of ions, and the evaporation of the water acted as an internal driving force to move the mineral ions out of the unit. Studies 


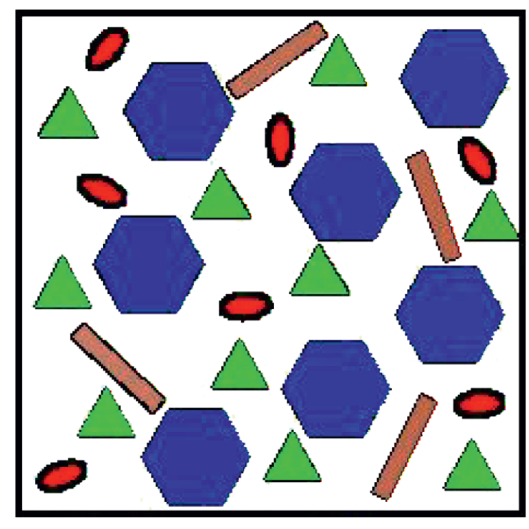

(a)

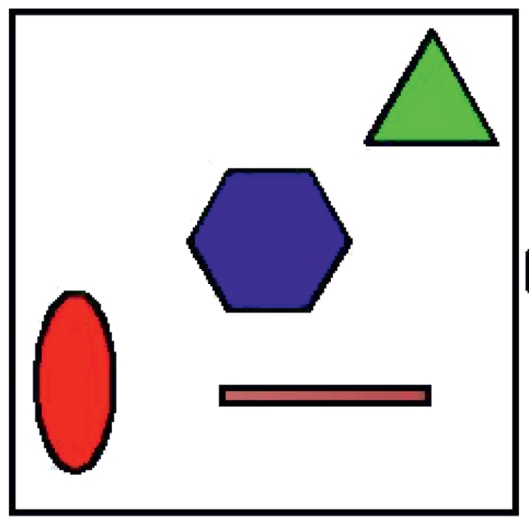

(c)

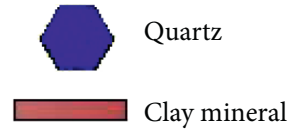

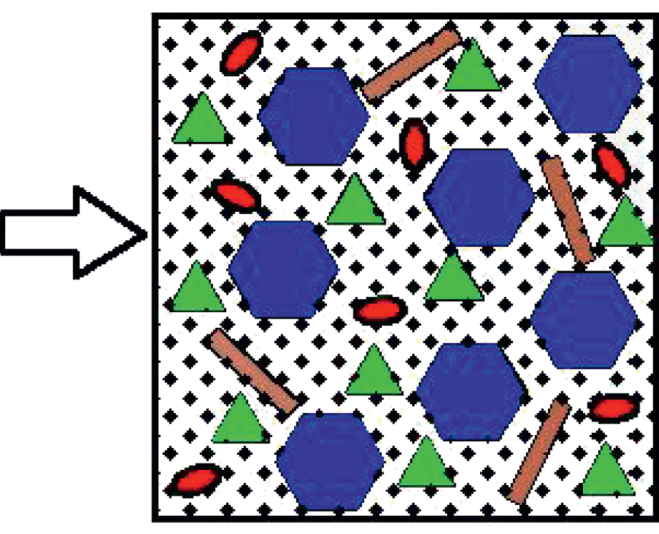

(b)

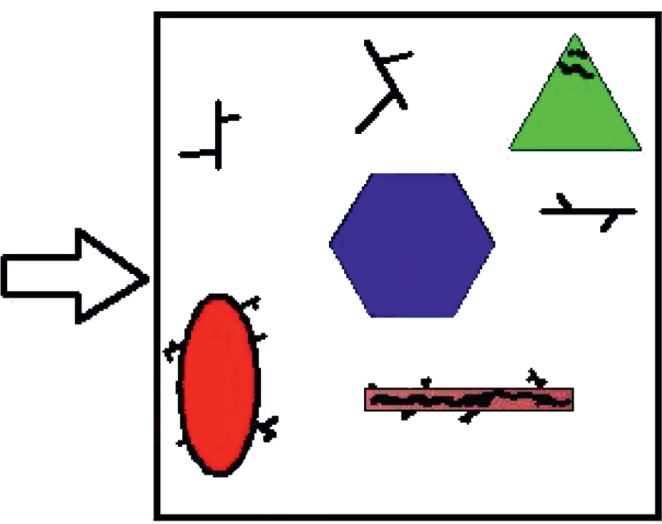

(d)

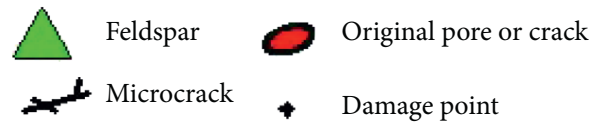

FiguRE 14: Microscopic process of a water-rock dry-wet cycle. (a) Original structure of feldspar sandstone. (b) Damage structure of feldspar sandstone. (c) Original unit structure. (d) Damage unit structures.

$[25,26]$ have shown that the solubility of feldspar is greater than that of kaolinite. Therefore, from a thermodynamic perspective, under certain conditions, feldspar has a tendency to transform into kaolinite, eventually leading to enlarged primary pores and secondary cracks and hence providing the spatial conditions for corrosion and dissolution later on.

With the above three actions, a number of secondary cracks were generated in the unit. As shown in Figure 14(d), these secondary cracks changed the structure of the unit. Because the feldspar sandstone sample was composed of a large number of units, numerous secondary cracks were produced in the feldspar sandstone after multiple dry-wet cycles. Such secondary cracks can be viewed as a large number of damaged points in the macrostructure of the feldspar sandstone, substantially changing the overall structure of feldspar sandstone, as shown in Figure 14(b). The large number of secondary pores that were produced essentially changed the overall structure of the feldspar sandstone. This resulted in a decrease in the wave velocity and an increase in the saturated water absorption for the physical properties as well as a decrease in the compressive strength for the mechanical properties of the feldspar sandstone, thereby increasing the number of fine cracks at the destruction of feldspar sandstone samples. Due to the corrosion and dissolution of the matrix by water, the surface roughness of the feldspar sandstone gradually increased. The above macroscopic and microscopic characteristics of the feldspar sandstone subjected to dry-wet cycles were also a manifestation of the damage to the feldspar sandstone from another perspective.

4.2. Analysis of the Weathering Mechanism of the Salt-Rock Interaction. According to the analysis of the results of the macroscopic physical and mechanical properties of the Group B feldspar sandstone, the physical and mechanical parameters of the feldspar sandstone after multiple dry-wet cycles were also weakened. In particular, the wave velocity, compressive strength, and elastic modulus were reduced by $33.27 \%, 73.44 \%$, and $72.39 \%$, respectively, while the saturated water absorption was increased by $36.98 \%$. The physical and mechanical properties of the Group B feldspar sandstone after dry-wet cycles deteriorated more following 


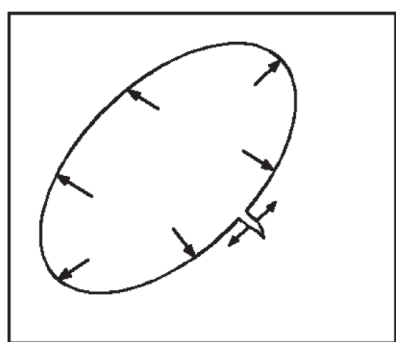

(a)

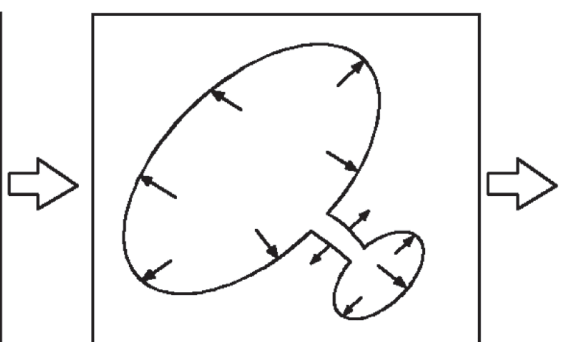

(b)

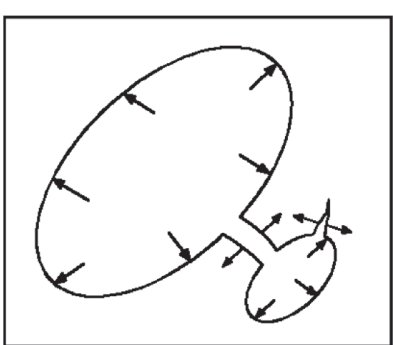

(c)

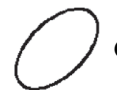

Original pore or crack

$\Longrightarrow$ Secondary crack

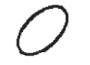

Secondary pore Crystalline stress

Figure 15: Microscopic process of the salt-rock dry-wet cycle. (a) Pore unit. (b) Crystallization that produced secondary pores or cracks. (c) More pores or cracks produced.

salt-rock interactions than following water-rock interactions, indicating the important influence of salt on the damage to the sandstone. The mechanism of the salt-rock interaction included the following:

(1) First, there were three effects of water-rock interaction. Since the erosive solution was a salt solution with sulfate as the solute and water as the solvent, the mechanism of the salt-rock interaction first included the three effects of water and rock.

(2) Second, there was the reaction between the sulfate ions and the feldspar sandstone components, as shown in formula (4). The minerals such as feldspar and calcite in the composition of the feldspar sandstone reacted with the sulfate ions to produce clay materials such as kaolinite and gypsum, which was similar to the effect of feldspar hydrolysis.

(3) The mechanism of the salt-rock interaction was that of the interaction between the salt solution and the feldspar sandstone. Therefore, in addition to the mechanism of the water-rock interaction and the ionic reaction, salt crystallization was also important. The site for salt crystallization, that is, the pores or cracks, could be considered as a unit in the study, as shown in Figure 15. When the feldspar sandstone underwent dry-wet cycles, the saturated salt solution entered the pores or cracks inside the feldspar sandstone. As the water evaporated, the salt gradually crystallized on the walls of the pores or cracks, causing compressive stress on the rock structures on both sides. When the compressive stress exceeded the tensile strength of the cement of the feldspar sandstone, secondary microcracks were produced, as shown in Figure 15(a). As the number of dry-wet cycles increased, the crystallization stress repeatedly acted on the microcracks, causing them to expand continuously to form secondary pores, as shown in Figure 15(b). During the subsequent dry-wet cycles, these secondary microcracks and the pores provided the sites for the salt enrichment in return, which caused the number of microcracks and pores to continuously increase, thus forming a vicious circle, as shown in Figure 15(c). With a sufficient source of salt, the crystallization caused stress damage to the structure of the feldspar sandstone as the surface area increased continuously. The structure of the feldspar sandstone changed under dry-wet cycles; that is, structural damage was generated. This was the mechanism of the damage to the feldspar sandstone.

Compared to the water-rock interaction, the participation of salt led to a relatively large number of secondary cracks and thus severe damage to the feldspar sandstone during the destruction process. As reflected in the macroscopic physical and mechanical properties, the wave velocity decreased, the saturated water absorption increased, and the compressive strength decreased. As reflected in the micro/ mesoscopic characteristics, a large number of microscopic pores were generated on the surface of the feldspar sandstone, the surface roughness increased rapidly, and a large amount of outside particles fell off. Additionally, the above phenomena indicated a higher degree of damage than that corresponding to the dry-wet cycles with water.

\section{Conclusion}

(1) At the macroscopic level, the Group A and B feldspar sandstones had increased saturated water absorption and decreased longitudinal wave velocities, peak strengths, and elastic moduli, as well as remarkable deformation characteristics. In addition, the variation rate of Group B was higher than that of Group A.

(2) At the micro/mesoscopic level, the Group A and B feldspar sandstones had decreased relative content of feldspar, increased relative content of kaolinite, enlarged microscopic pores, more microcracks, and larger surface height deviations. Additionally, the variation rate of Group B was higher than that of Group A.

(3) The weathering mechanism of the feldspar sandstone included water-rock interaction and salt-rock interaction. The weathering mechanism of the waterrock interaction consisted of three effects, namely, the hydrolysis of $\mathrm{K}-\mathrm{Na}$ feldspar, the water swelling of the clay minerals such as kaolinite and the dissolution of soluble minerals. The weathering 
mechanism of the salt-rock interaction included, in addition to the above three effects, salt crystallization in the pores or fissures and the chemical reaction between the minerals (e.g., feldspar and calcite) and sulfate. In particular, the salt crystallization was the most remarkable for the deterioration of the feldspar sandstone.

\section{Data Availability}

All data used in this article are available from the corresponding author by request.

\section{Conflicts of Interest}

The authors declare that they have no conflicts of interest.

\section{Acknowledgments}

This work was supported by the National Key R\&D Plan of China (Grant no. 2017YFC1503100) and the National Natural Science Foundation of China (Grant no. 51474121). The authors thank LetPub (https://www.letpub.com) for its linguistic assistance during the preparation of this manuscript.

\section{References}

[1] R. Z. Liu, B. J. Zhang, H. Zhang, and M. F. Shi, "Deterioration of Yungang grottoes: diagnosis and research," Journal of Cultural Heritage, vol. 12, no. 4, pp. 494-499, 2011.

[2] X.-S. Wang, L. Wan, J. Huang, W. Cao, F. Xu, and P. Dong, "Variable temperature and moisture conditions in Yungang Grottoes, China, and their impacts on ancient sculptures," Environmental Earth Sciences, vol. 72, no. 8, pp. 3079-3088, 2014.

[3] S. J. Yan, Y. Fang, J. H. Liu, and S. E. Tan, "Deterioration experiment with soluble salt on sandstone of Yungang grottoes and its model creation," Rock and Soil Mechanics, vol. 34, pp. 3410-3416, 2013, in Chinese.

[4] S. J. Yan, J. Q. Chen, Y. Dou, and P. Sun, "Characteristics of Yungang grottoes sandstone and weathering simulation tests," Geoscience, vol. 29, pp. 442-447, 2015, in Chinese.

[5] Y. Qin, Y. Wang, L. Li, and J. Huang, "Experimental weathering of weak sandstone without direct water participation by using sandstone from the Yungang grottoes in Datong, China," Rock Mechanics and Rock Engineering, vol. 49, no. 11, pp. 4473-4478, 2016.

[6] H. Y. Yao, Z. H. Zhang, C. H. Zhu, Y. C. Shi, and Y. Li, "Experimental study of mechanical properties of sandstone under cyclic drying and wetting," Rock and Soil Mechanics, vol. 31, pp. 3704-3714, 2010, in Chinese.

[7] M. A. Coombes and L. A. Naylor, "Rock warming and drying under simulated intertidal conditions, part II: weathering and biological influences on evaporative cooling and near-surface micro-climatic conditions as an example of biogeomorphic ecosystem engineering," Earth Surface Processes and Landforms, vol. 37, no. 1, pp. 100-118, 2012.

[8] M. C. Torres-Suarez, A. Alarcon-Guzman, and R. Berdugo-De Moya, "Effects of loading-unloading and wetting-drying cycles on geomechanical behaviors of mudrocks in the Colombian Andes," Journal of Rock Mechanics and Geotechnical Engineering, vol. 6, no. 3, pp. 257-268, 2014.
[9] B. Du, H. B. Bai, Z. G. Ma, M. Li, and G. M. Wu, "Experimental study on the dynamic tensile properties of redsandstone after cyclic wetting and drying," Chinese Journal of Rock Mechanics and Engineering, vol. 37, pp. 1671-1679, 2018, in Chinese.

[10] H. F. Deng, J. L. Li, K. W. Wang, J. Liu, M. Zhu, and T. Lu, "Research on secondary porosity changing law of sandstone under saturation-air dry cycles," Rock and Soil Mechanics, vol. 33, pp. 483-488, 2012, in Chinese.

[11] Y. Fu, Z. J. Wang, X. R. Liu et al., "Meso damage evolution characteristics and macro degradation of sandstone under wetting-drying cycles," Chinese Journal of Geotechnical Engineering, vol. 39, pp. 1653-1661, 2017, in Chinese.

[12] A. Özbek, "Investigation of the effects of wetting-drying and freezing-thawing cycles on some physical and mechanical properties of selected ignimbrites," Bulletin of Engineering Geology and the Environment, vol. 73, no. 2, pp. 595-609, 2014.

[13] P. D. Sumner and M. J. Loubser, "Experimental sandstone weathering using different wetting and drying moisture amplitudes," Earth Surface Processes and Landforms, vol. 33, no. 6, pp. 985-990, 2008.

[14] H. M. Zhang, G. D. Ma, and B. Y. Shu, "A discussion of the treatment of water-seepage disease of the stone carvings in the Yungang grotto near Datong," Hydrogeology \& Engineering Geology, vol. 31, pp. 64-67, 2004, in Chinese.

[15] F. Guo and G. H. Jiang, "Distribution of soluble salts and sulfur isotope in the Yungang Grottoes, Datong," Hydrogeology \& Engineering Geology, vol. 40, pp. 126-130, 2013, in Chinese.

[16] M. Duda and J. Renner, "The weakening effect of water on the brittle failure strength of sandstone," Geophysical Journal International, vol. 192, pp. 1091-1108, 2000.

[17] X. R. Liu, M. H. Jin, D. L. Li, and L. Zhang, "Strength deterioration of a shaly sandstone under dry-wet cycles: a case study from the three gorges reservoir in China," Bulletin of Engineering Geology and the Environment, vol. 76, pp. 1-15, 2017.

[18] S. P. Ma and H. Zhou, "Surface strain field evolution of rock specimen during failure process," Chinese Journal of Rock Mechanics and Engineering, vol. 27, pp. 1668-1673, 2008, in Chinese.

[19] S. P. Ma, L. G. Wang, and Y. H. Zhao, "Experimental study on deformation field evolution during failure procedure of a rock borehole structure," Rock and Soil Mechanics, vol. 27, pp. 1083-1086, 2006, in Chinese.

[20] I. Farina, F. Fabbrocino, F. Colangelo, L. Feo, and F. Fraternali, "Surface roughness effects on the reinforcement of cement mortars through 3D printed metallic fibers," Composites Part B: Engineering, vol. 99, pp. 305-311, 2016.

[21] A. R. Ismail, M. Z. Jaafar, W. R. W. Sulaiman, I. Ismail, and N. Y. Shiunn, "Identification of sandstone core damage using scanning electron microscopy," in Proceedings of the Advanced Materials Conference, vol. 28-29, pp. 79-83, Langkawi, Malaysia, November 2016.

[22] M. Steiger, "Crystal growth in porous materials-II: influence of crystal size on the crystallization pressure," Journal of Crystal Growth, vol. 282, no. 3-4, pp. 470-481, 2005.

[23] P. Theoulakis and A. Moropoulou, "Microstructural and mechanical parameters determining the susceptibility of porous building stones to salt decay," Construction and Building Materials, vol. 11, no. 1, pp. 65-71, 1997.

[24] T. Belem, F. Homand-Etienne, and M. Souley, "Quantitative parameters for rock joint surface roughness," Rock Mechanics and Rock Engineering, vol. 33, no. 4, pp. 217-242, 2000. 
[25] Y. Chen, C. J. Wang, X. F. Sun et al., "Progress on mineral solubility and mechanism of dissolution secondary porosity forming in clastic reservoir," Bulletin of Mineralogy, Petrology and Geochemistry, vol. 34, pp. 830-836, 2015, in Chinese.

[26] X. J. Luo, W. D. Yang, R. X. Li et al., "Effects of $\mathrm{pH}$ on the solubility of the feldspar and the development of secondary porosity," Bulletin of Mineralogy, Petrology andGeochemistry, vol. 20, pp. 103-107, 2001, in Chinese. 